\title{
CORRIGENDUM
}

\section{Wild-type blocking polymerase chain reaction for detection of single nucleotide minority mutations from clinical specimens}

\author{
PL Dominguez and MS Kolodney
}

Oncogene (2006) 25, 656. doi:10.1038/sj.onc.1209332

Correction to: Oncogene 2005; 24: 6830-6834. doi:10.1038/sj.onc.1208832; Published online 22 August 2005

Since publication of the above manuscript, the authors have identified the following errors:

(1) Figure $2 \mathrm{~b}$ is labeled incorrectly. A corrected version of Figure $2 b$ is given below.

(2) The caption for Figure 2 states incorrect concentrations of flanking primers. Currently, the caption reads, ' $2.5 \mu \mathrm{l}$ of each flanking primer $(32.5 \mathrm{nmol}$ forward and $33.6 \mathrm{nmol}$ reverse)'. The correct concentrations should read, ' $2.5 \mu \mathrm{l}$ of each flanking primer $(100 \mu \mathrm{M}$ forward and $100 \mu \mathrm{M}$ reverse)'.

(3) The caption for Figure 3 also lists incorrect concentrations of primers. Currently, the caption reads, ' $1 \mu$ l of each primer $(28.0 \mathrm{nmol}$ forward and $27.79 \mathrm{nmol}$ reverse)'. The correct concentrations should read, ' $1 \mu \mathrm{l}$ of each primer $(100 \mu \mathrm{M}$ forward and $100 \mu \mathrm{M}$ reverse)'.

(4) Lastly, the results section states an incorrect concentration of blocker necessary to prevent a visible band during wild-type blocking PCR (WTBPCR). Currently, the results read, 'As shown in Figure $2 \mathrm{~b}$, a minimum of $0.01 \mathrm{nM}$ of blocker was necessary to prevent a visible band in the PCR reaction.' The correct concentration of blocker should read, 'As shown in Figure 2b, a minimum of $0.1 \mu \mathrm{M}$ of blocker was necessary to prevent a visible band in the PCR reaction.'

The authors apologize for these errors, but we feel that these changes are very important since they are necessary to perform our technique accurately.

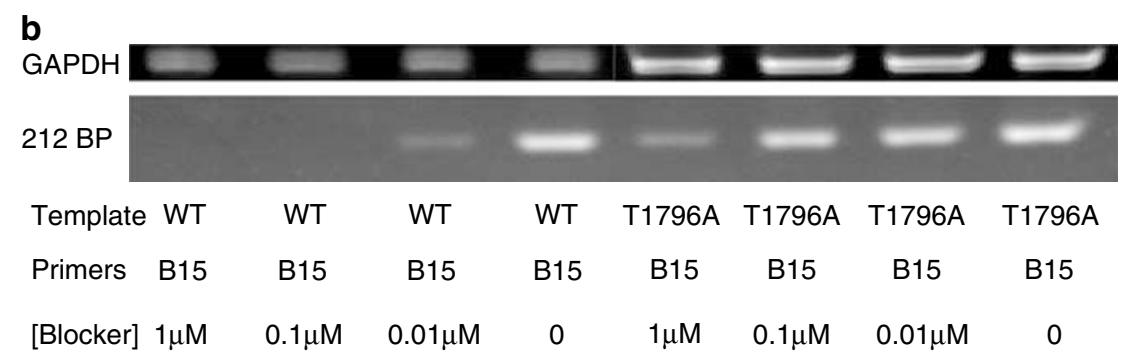

